\title{
Mein Weg
}

My Way

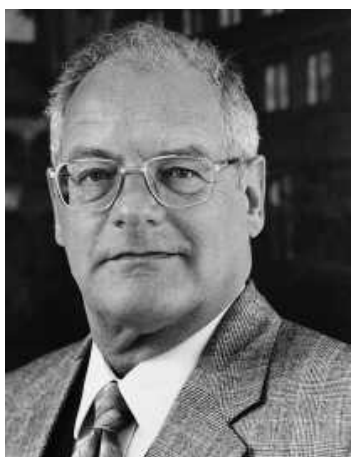

Prof. Dr. E. G. Jung
„Tief ist der Brunnen der Vergangenheit“ stellt Thomas Mann (1875-1955) als Eröffnung der historischen Romantetralogie „Josef und seine Brüder“ voran. Er weist damit auf die Ursprungsmythen des Kulturgedächtnisses zurück. Ähnliches gilt auch für das persönliche kulturelle Gedächtnis und dasjenige von und über Einrichtungen. Es gilt auch für unsere Zeitschrift. Deshalb haben wir dem 30-jährigen Jubiläum vor zwei Jahren hohen Wert zugemessen und die Gründungszeit festgehalten. Dies wirkt sich aus, nach innen wie nach außen. Die Zeitschrift steht gut da, gerüstet für die Zukunft. Und dennoch, oder gerade deswegen, gilt nach wie vor, dass jedes Ding seine Zeit hat. Dies gilt nun auch für mich. Ich hatte die Zeit des Wachstum und der Behauptung der Aktuellen Dermatologie mitgestaltet und erlebt, die hohe Zeit des Jubiläums begangen und die Phase des Überganges vorbereitet. Nun ist meine Zeit des Loslassens und Zurücktretens gekommen.

In den vergangenen 30 Jahren, 1977-2006, habe ich unserer Zeitschrift als Herausgeber gedient, in den letzten 3 Jahren zudem als federführender Träger der Redaktion. Mit über 100 eigenen Artikeln habe ich zum Gedeihen der Zeitschrift beigetragen. Ich habe dies alles gerne, mit Engagement und großer Freude getan. Jetzt möchte ich mich für die gute Zusammenarbeit beim Georg Thieme Verlag, den Mitherausgebern, den Autoren und allen Lesern sehr herzlich bedanken. Viele sind es gewesen, einst und jetzt, die mich in den 30 Jahren begleiteten, die mich anregten und mich bereicherten. Es war schön, ein Thieme-Autor gewesen zu sein.

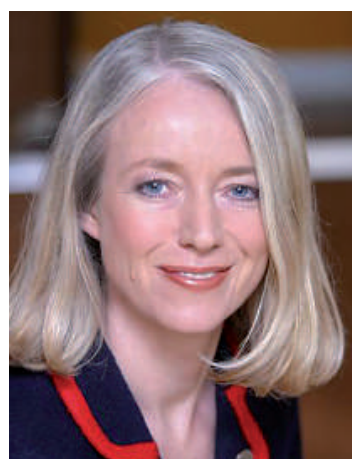

Prof. Dr. Christiane Bayerl

Unsere Zeitschrift Aktuelle Dermatologie steht gut da. Mit breiter Palette dient sie der Vermittlung der wissenschaftlichen Errungenschaften unseres Faches in die Praxis, unterstützt die permanente Fort- und Weiterbildung und öffnet jungen Kollegen ein Forum für interessante Mitteilungen und Kasuistiken. Sie ist in 32 Jahren gereift und wird anerkannt. Nun steht die Herausgeberschaft verjüngt formiert bereit und Frau Prof. Dr. med. Christiane Bayerl, Direktorin der Klinik für Dermatologie und Allergologie in Wiesbaden, ist mit der federführenden Redaktion betraut. Ihr und unserer Zeitschrift wünsche ich alles Gute, Erfolg und Anerkennung!

E. G. Jung, Heidelberg
Bibliografie

DOI $10.1055 / \mathrm{s}-2006-945052$ Akt Dermatol 2006; 32; 501

(c) Georg Thieme Verlag KG . Stuttgart · New York ISSN 0340-2541

Korrespondenzadresse Prof. Dr. Ernst G. Jung Maulbeerweg 20 . 69120 Heidelberg Ernst.G.Jung@t-online.de 